\title{
Effect of diet on blood viscosity in healthy humans: a systematic review
}

Hamideh Naghedi-Baghdar ${ }^{1}$, Seyed-Mohammad Nazari² ${ }^{2}$ Ali Taghipour ${ }^{3}$, Mohsen Nematy ${ }^{4}$, Sadegh Shokri ${ }^{5}$, Mohammad-Reza Mehri ${ }^{1}$, Tahereh Molkara ${ }^{1}$, Roghayeh Javan ${ }^{6}$

${ }^{1}$ Student Research Committee, Faculty of Persian and Complementary Medicine, Mashhad University of Medical Sciences, Mashhad, Iran

${ }^{2}$ Faculty of Persian and Complementary Medicine, Mashhad University of Medical Sciences, Mashhad, Iran

${ }^{3}$ Department of Biostatistics and Health Sciences Research Center, School of Health, Mashhad University of Medical Sciences, Mashhad, Iran

${ }^{4}$ Biochemistry and Nutrition Research Center, Faculty of Medicine, Mashhad University of Medical Sciences, Mashhad, Iran

${ }^{5}$ Faculty of Persian and Complementary Medicine, Mashhad University of Medical Sciences, Mashhad, Iran

${ }^{6}$ Traditional and Complementary Medicine Research Center, Sabzevar University of Medical Sciences, Sabzevar, Iran

Type of article: Systematic review

\begin{abstract}
Background: Increased whole blood viscosity is associated with increased risk of morbidity and mortality of several life-threatening diseases, including cardiovascular and cerebrovascular disease. The effect of diet on human health has been indicated in many studies, and a health dietary pattern can reduce the incidence of several chronic diseases.

Objective: The aim of this systematic review was to assess the effect of diet on blood viscosity and related parameters such as haematocrit (HCT).

Methods: This systematic review was carried out in 2017. MEDLINE, Embase, Scopus, Web of Science, and the Cochrane Central Register of Controlled Trials were searched from inception to 2 May 2017. We selected and included randomized clinical trials (RCTs) in the study. The inclusion criteria were articles that describe the effect of any types of local and traditional diet on blood viscosity in apparently healthy individuals.

Results: Three randomized controlled trials were included in this systematic review. Different diets were used in the included trials. In one study, ingested dried-bonito broth (DBB) for four weeks, significantly reduced the blood passage time in the intervention group from $55.4 \pm 3.4$ to $47.6 \pm 2.0 \mathrm{sec}$ (mean $\pm \mathrm{SEM}, \mathrm{p}<0.05$ ) compared with no significant change in the placebo group. Another study has shown significantly increased blood fluidity score in a vegetarian group in contrast to the control group after six weeks. In the last study, plasma viscosity was significantly decreased in a group which used onion-olive-oil capsules compared to the placebo group, with a highly significant difference between the two groups $(\mathrm{p}=0.0015)$.

Conclusions: Our components of food diets may decrease blood viscosity in health status. Better and expanded methodology may improve our results.
\end{abstract}

Keywords: Blood Viscosity, Blood Fluidity, Diet, Nutrition

\section{Introduction}

Blood viscosity (BV) is an important blood property, and plays a key role in maintaining vascular homeostasis. Blood viscosity is mainly determined by haematocrit, plasma viscosity, the deformability and aggregation of red blood cells (RBCs), and shear rate $(1,2)$. Blood viscosity rising, may increase morbidity/mortality of cardiovascular patients $(3,4)$. Moreover, abnormal blood viscosity is closely related to the pathogenesis, development, and

\section{Corresponding author:}

Dr. Roghayeh Javan, Traditional and Complementary Medicine Research Center, Sabzevar University of Medical Sciences, Sabzevar, Iran. Tel: +98.5144220869, Email: r_javan51@yahoo.com

Received: August 29, 2017, Accepted: November 16, 2017, Published: March 2018

iThenticate screening: November 09, 2017, English editing: January 30, 2018, Quality control: February 15, 2018

This article has been reviewed / commented by three experts

(C) 2018 The Authors. This is an open access article under the terms of the Creative Commons Attribution-NonCommercialNoDerivs License, which permits use and distribution in any medium, provided the original work is properly cited, the use is non-commercial and no modifications or adaptations are made. 
prognosis of several life-threatening diseases including chronic cerebral infarction, transient ischemic attack, diabetes mellitus, haemorrhagic shock, renal disease, and risk factors for stroke $(5,6)$. Two therapeutic procedures are available for decreasing blood viscosity: direct and indirect. Plasma exchange, phlebotomy, and rheopheresis are applied directly, whereas in indirect method, we regulate erythrocytes, platelets, and endothelial cells etc., that may have an effect on blood viscosity, $(1,2)$. Diet as a complex variable, is often used with multiple approaches to examine its association with the risk of disease (7). The effect of diet on human health has been indicated in many clinical and population-based studies, which provide evidence that a health dietary pattern can reduce the incidence of cardiovascular disorders, cancers, diabetes, and several other chronic diseases $(8,9)$. The relationship between some nutritional-related diseases such as hypertriglyceridemia, hypoalbuminemic disorders, and diabetes mellitus, and blood and plasma viscosity has been demonstrated in several studies $(6,10)$. Based on recent findings, plantbased foods and avoiding animal-based foods can decrease coronary artery diseases (11). A systematic review study on randomized controlled trials was carried out to assess the association between diet and blood viscosity.

\section{Material and Methods}

\subsection{Research design and search strategy}

The present study was carried out in 2017 , to design a systematic search to evaluate the randomized clinical trials (RCTs) that examined the effect of diet on blood viscosity in apparently healthy individuals. We searched MEDLINE, Embase, Scopus, Web of Science, and the Cochrane Central Register of Controlled Trials from inception to 2 May 2017, which is limited by English language and human studies. The keywords that were used alone or in combination included Blood viscosity or Haemorheology or Blood rheology or Blood fluidity, or Polycythaemia or Blood circulation or Microcirculation or Blood flow or Blood indices or Haematological parameters, Diet or Food or Foodstuff or Functional food or Recipe or Nutrition or Meal or Dish or Chow or Cuisine or Traditional or Mediterranean diet or Complementary medicine or Alternative medicine).

\subsection{Inclusion and exclusion criteria}

The RCTs that evaluated diet affecting blood viscosity in apparently healthy individuals were considered. Studies on individuals with organ disease, obesity, hypertension, hyperlipoproteinemia, diabetes, cardiocerebrovascular disease, smoking, or drug treatment and other similar cases were excluded. The experimental interventions included any types of local or traditional diet without timing usage, dosage, or preparation method restriction. We rejected the studies without random allocation or clear randomization. Whole blood viscosity, plasma viscosity, blood fluidity (blood passage time), blood fluidity score (BFS), haematocrit and side-effects of the diet were our primary outcomes. The secondary outcomes were erythrocyte aggregation, systolic blood pressure, diastolic blood pressure, platelet aggregation, and other laboratory tests. Two authors independently did the article review for eligibility and entry criteria. For identical opinion; differences were discussed and finally, extracted data included time and place, author, methodology, method of use/ type/ amount/ of the diet, details of comparative nutrition regimen, duration of treatment, follow-up timing, case characteristics, number of randomized cases, number lost to follow-up, primary and secondary outcomes and adverse events.

\subsection{Quality assessment}

Eligible RCTs were qualified by Cochrane Collaboration's tool for assessment of risk bias (12). One researcher assessed, another cross-checked it.

\section{Results}

A total of 1,894 articles were gathered by our keywords. By reference searching, six articles were obtained. A flowchart showing the process of study selection is presented in Figure 1. After the elimination of duplicate articles, 1,208 articles remained. By title reading, 1,091 titles were determined non-relevant. After abstracts review of 117 articles, 107 articles were disregarded; 101 of which were non-clinical, review articles or had no defined criteria and six articles were in non-English and lacked an abstract or principle of articles. Subsequently, 10 articles reporting on clinical trials remained; we rejected seven of the 10 articles for lack of defined criteria. Finally, we confirmed three clinical trials as eligible articles for study.

\subsection{Study design}

Three RCTs involving 68 participants were considered eligible. These studies reported random allocation of participants that had diet with its effect on blood viscosity. One of them was a pilot study. Two of the study sites were in Germany and Japan, and the third study site was not known. These articles were not written with any financial support from pharmaceutical companies or factories. 


\subsection{Participants}

Sixty-eight men and women who participated in these studies were from three countries. One study was performed on 24 healthy adult subjects aged $42.0 \pm 2.0$; the second study was performed on 30 apparently healthy volunteers, 15 men and 15 women; and the third study was performed on 14 women (aged 18-35 years). All participants were healthy adult subjects.

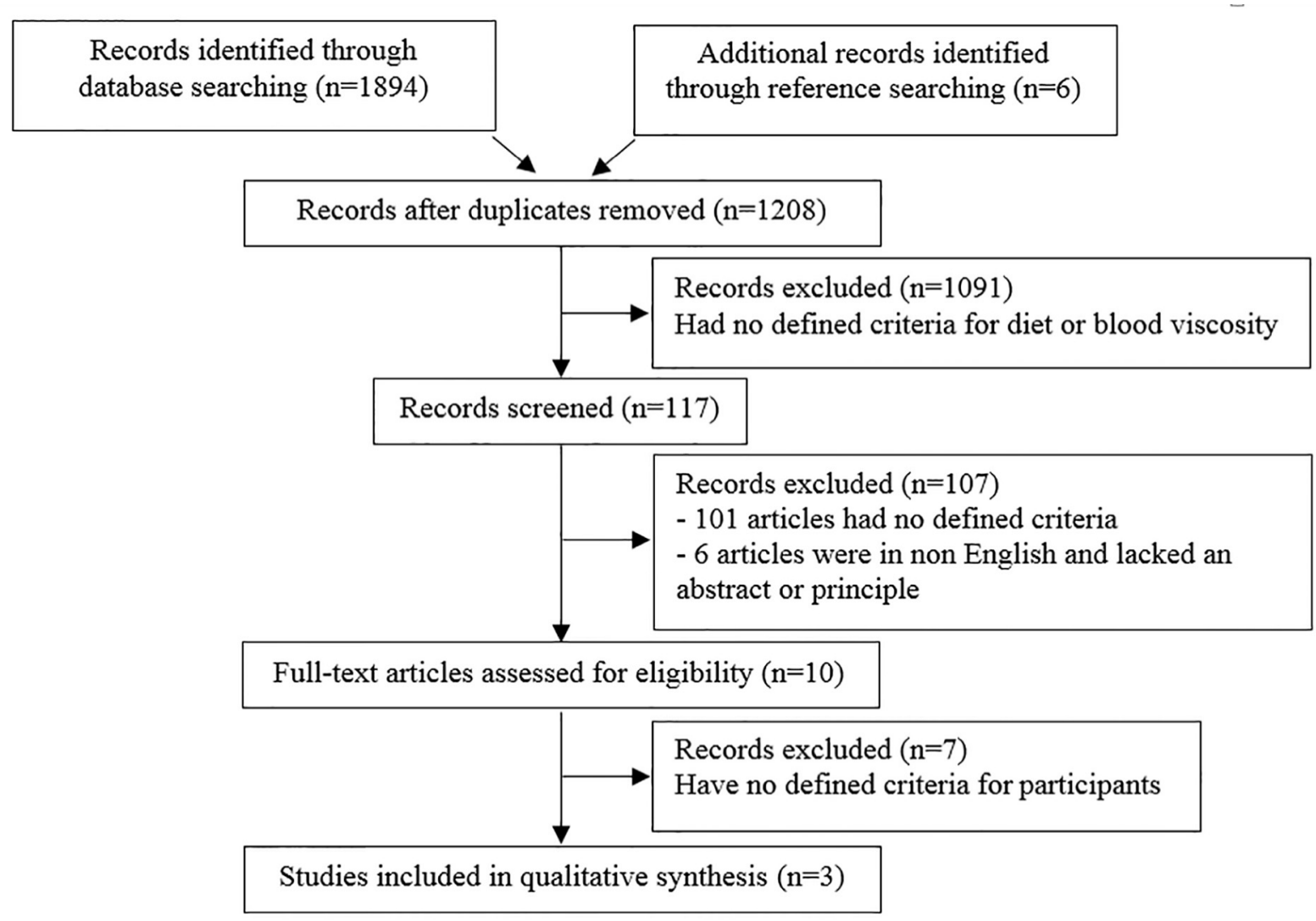

Figure 1. Study flow chart.

\subsection{Interventions}

Three diets were tested in the RCTs. One study evaluated the effects of dried-bonito broth (DBB) compared with placebo for four weeks. Another study assessed the effect of an onion-olive-oil maceration product compared with placebo with a subsequent crossover after a washout phase of 14 days. The last study assessed a normaldiet and limited the total calorie intake to 800-900 kcal/day compared with a diet with the same calorie intake, and also stopped the consumption of meat, fish, or products of meat or fish for six weeks.

\subsection{Risk of bias within studies}

By using Cochrane Collaboration's tool, we assessed the risk of bias in studies, Table 1 shows the summarized results. Only randomized trials were accepted for reviewing. Allocation concealment, and blinding of patient and treating physician, were performed in two of the three trials. All three studies were free of selective reporting.

Table 1. Risk of bias

\begin{tabular}{|l|l|l|l|l|l|l|l|l|}
\hline $\begin{array}{l}\text { ref. } \\
\text { no. }\end{array}$ & $\begin{array}{l}\text { Random } \\
\text { Sequence } \\
\text { Generation }\end{array}$ & $\begin{array}{l}\text { Allocation } \\
\text { Concealment }\end{array}$ & $\begin{array}{l}\text { Blinding (Study } \\
\text { patient) }\end{array}$ & $\begin{array}{l}\text { Blinding } \\
\text { (treating } \\
\text { physician) }\end{array}$ & $\begin{array}{l}\text { Blinding of } \\
\text { clinical } \\
\text { outcome }\end{array}$ & $\begin{array}{l}\text { Incomplete } \\
\text { outcome data } \\
\text { addressed }\end{array}$ & $\begin{array}{l}\text { Free of } \\
\text { selective } \\
\text { reporting }\end{array}$ & $\begin{array}{l}\text { Free of } \\
\text { other bias }\end{array}$ \\
\hline 13 & + & + & + & - & - & + & + \\
\hline 14 & + & + & - & - & - & - & + & - \\
\hline 15 & + & + & + & - & - & + & + \\
\hline
\end{tabular}




\subsection{Outcomes}

In the study of Yoshizu Nozawa, blood fluidity was measured. Blood passage time significantly decreased by DBB ingestion from $55.4 \pm 3.4$ to $47.6 \pm 2.0 \mathrm{sec}$ (mean $\pm \mathrm{SEM}, \mathrm{p}<0.05$ ). In the placebo group, this time had no significant difference (52.4 \pm 3.4 to $51.4 \pm 2.6 \mathrm{sec}$, mean $\pm \mathrm{SEM}$ ). This finding, indicated that DBB decreased blood fluidity. And also, after DBB ingestion; Level of d-ROMs [a biomarker of oxidative stress] significantly fell from $337.2 \pm 18.5$ to $316.5 \pm 12.9$ Carrotelli units (Carr. U.) (mean \pm SEM, $\mathrm{p}<0.05$ ). This suggests that DBB can reduce oxidative stress (13). In the E. Ernst study, the blood fluidity score is evaluated. In their two groups, BFS at baseline was almost equal. Three weeks after diet intervention, no significant longitudinal change was observed within either group ($2.8 \pm 1.7$ in vegetarians and $-1.6 \pm 2.1$ in controls); thus, at the three-week measuring point, no significant intergroup difference was noted. In the second half of diet intervention, BFS (three- versus six-week values) significantly increased in vegetarians $(-0.9 \pm 1.9)$ and blood fluidity. In the control group $(-3.2 \pm 1)$, there was a significant decreased fluidity (compared to baseline, there were no significant longitudinal changes in either group). Thus, at the end of the diet intervention, BFS was significantly different between the two groups (14). In the study of Ulrich Kalus, plasma viscosity is measured. Onion capsules significantly decrease $0.03 \mathrm{mPa} . \mathrm{s}$, in mean plasma viscosity without difference to the placebo group. In the intervention phase (before: $1.28 \pm 0.06$, after $5 \mathrm{~h}: 1.25 \pm 0.05$ ) compared with the placebo phase (before: $1.27 \pm 0.07$, after $5 \mathrm{~h}: 1.27 \pm 0.08$ ). The difference of plasma viscosity between the two treatment groups was highly significant $(\mathrm{p}=0.0015)$. Haematocrit was measured in this study. There are no significant differences in haematocrit (intervention phase, before: $41.3 \pm 4.3$, after $5 \mathrm{~h}: 40.5 \pm 4.0$ and placebo phase, before: $40.7 \pm 4.6$, after $5 \mathrm{~h}: 40.1 \pm 4.3$ ), $\mathrm{p}=0.610$. Also, erythrocyte aggregation in the intervention phase (before: 12.9 \pm 3.6 , after $5 \mathrm{~h}: 11.9 \pm 3.4$ ) had no significant differences compared with the placebo phase (before: $12.2 \pm 4.3$, after 5h: 12.1 \pm 4.7$), p=0.058$. A slight but significant decrease in systolic blood pressure is found in the intervention phase (before: $120.7 \pm 10.5$, after $5 \mathrm{~h}: 117.7 \pm 10.4$ ) compared with the placebo phase (before: $120.4 \pm 12.2$, after $5 \mathrm{~h}$ : $118.7 \pm 11.9), p=0.0498$. There are no significant changes in diastolic blood pressure (15). No adverse events were reported during the three studies. The features of these three studies are summarized in Table 2.

\subsection{Dried-bonito broth compared with placebo}

Yoshizu Nozawa et al. conducted a randomized double-blind placebo-controlled study in 24 healthy adult subjects with mean age 42.0 \pm 2.0 (mean \pm SEM) years. Each group had 7 males and 5 females. They were screened, and then intervention was applied. They were randomly divided into two groups and had no significant differences in blood fluidity (measured by MC-FAN). Participants received dried-bonito broth (DBB) or placebo over 4 weeks. Blood fluidity and oxidative stress were measured before and after intervention. Participants completed a questionnaire during the study period. Commercial dried-bonito broth, named 'Hondzukuri ichiban-dashi' (Ajinomoto Co., Inc., Tokyo Japan), produced via a hot-water extraction process from DBB, was used as an active dietary supplement. The placebo consisted of dried-bonito flavour, caramel, and sodium chloride, and was prepared so that the two test diets were indistinguishable. The subjects ingested $125 \mathrm{ml}$ of the diet every morning in addition to their regular diet, for four weeks. With a microchannel array flow analyser and passage time of $100 \mu 1$ of heparinized whole blood through the microchannel array; blood fluidity was measured. Oxidative stress was evaluated as a level of the derivative of reactive oxygen metabolites (d-ROMs) by a free radical analysis system (FRAS) (13).

\subsection{Vegetarian diet compared with meat eating diet}

E. Ernst et al. reported a randomized clinical trial pilot study in order to test the hypothesis that a vegetarian diet can alter the fluidity of blood. A total of 14 healthy females, who had normal omnivorous diets and without chronic medication/overweightness were randomly allocated into two groups. Group A followed their usual diet but limited the total calorie intake to $800-900 \mathrm{kcal}$ per day. Group B followed the same calorie intake and a diet without meator fish products. These diets were administered in 6 weeks. Participants received detailed diet instructions before the study. By a structured interview; their compliance was considered during visits in the 3rd and 6th week (14).

\subsection{Onion-olive-oil capsules compared with placebo}

A randomized, placebo-controlled, double-blind crossover trial by Ulrich Kalus et al. in three centres, for verifying the primary investigation results by evaluating the effect of an onion-olive-oil maceration remedy on arterial blood pressure and blood fluidity, was performed on 30 healthy subjects ( 15 men and 15 women aged 18 years and older). Participants were randomly allocated to the intervention or placebo group (15 subjects in each group), and then crossover after 14 days as washout phase (15). Fasting subjects arrived at 7 a.m. at the study rooms. Measurements started after a one-hour resting period. Before and five hours after the intake of four capsules, each containing 270 $\mathrm{mg}$ of an onion-olive-oil maceration product manufactured by Phyt-Immun, Homburg/Saar Germany (corresponding to a mean daily dose of $2.5 \mathrm{~g}$ fresh onions), or identically prepared placebo capsules which were 
matched for size and appearance, with 0.251 of unsweetened fruit tea, blood pressure and heart rate were measured, and blood samples for the determination of haematocrit, plasma viscosity, and erythrocyte aggregation were drawn. Subjects were prohibited from eating, or leaving the study rooms during the $5 \mathrm{~h}$ investigation. Maximum allowed fluid intake was 0.5 litres (15).

Table 2. Characteristics of the included studies

\begin{tabular}{|c|c|c|c|c|c|}
\hline $\begin{array}{l}\text { Ref. } \\
\text { no. }\end{array}$ & Study design & Samples & Interventions & Primary outcome & Secondary outcome \\
\hline 15 & $\begin{array}{l}\text { Randomized, } \\
\text { placebo- } \\
\text { controlled, } \\
\text { double- blind } \\
\text { with cross-over } \\
\text { design }\end{array}$ & $\begin{array}{l}\text { Thirty apparently } \\
\text { healthy volunteers, } \\
15 \text { men and } 15 \\
\text { women, with normal } \\
\text { blood fluidity, } \\
\text { without organ } \\
\text { disease, obesity, } \\
\text { hypertension, } \\
\text { hyperlipoproteinemia } \\
\text { or drug treatment } \\
\text { other than oral } \\
\text { contraceptives } \\
\end{array}$ & $\begin{array}{l}\text { Group 1: Four capsules } \\
\text { (each } 270 \mathrm{mg} \text { ) of onion- } \\
\text { olive-oil maceration } \\
\text { product. } \\
\text { Group 2: Identically } \\
\text { prepared placebo } \\
\text { capsules, with } 0.251 \text { of } \\
\text { unsweetened fruit tea, } \\
\text { fluid intake was } \\
\text { restricted to a total } \\
\text { amount of } 0.51 .\end{array}$ & $\begin{array}{l}\text { Plasma viscosity, } \\
\text { Hematocrit, side effects: } \\
\text { There was a significant mean decrease } \\
\text { in plasma viscosity of } 0.03 \mathrm{mPa} \mathrm{s} \text {, in } \\
\text { group } 1 \text {, whereas there was no change } \\
\text { in group } 2 . \text { There were no significant } \\
\text { differences in hematocrit before and } \\
\text { after treatment in both groups. No } \\
\text { adverse events were reported during the } \\
\text { study. }\end{array}$ & $\begin{array}{l}\text { Erythrocyte aggregation, blood } \\
\text { pressure, heart rate: } \\
\text { There were no significant differences } \\
\text { in erythrocyte aggregation before and } \\
\text { after treatment in both groups. There } \\
\text { was a slight but significant decrease } \\
\text { in systolic blood in group } 1 \text {. There } \\
\text { were no significant changes in } \\
\text { diastolic blood pressure and heart rate } \\
\text { before and after treatment in both } \\
\text { groups. }\end{array}$ \\
\hline 13 & $\begin{array}{l}\text { Randomized } \\
\text { double-blind } \\
\text { placebo- } \\
\text { controlled }\end{array}$ & $\begin{array}{l}\text { Twelve healthy adult } \\
\text { subjects, } 7 \text { men and } 5 \\
\text { women }\end{array}$ & $\begin{array}{l}\text { Group 1: Ingested } \\
\text { commercial, dried-bonito } \\
\text { broth. } \\
\text { Group 2: The placebo } \\
\text { consisted of dried-bonito } \\
\text { flavor, caramel, and } \\
\text { sodium chloride, and } \\
\text { was prepared so that the } \\
\text { two test diets were } \\
\text { indistinguishable. Both } \\
\text { groups ingested } 125 \mathrm{ml} \\
\text { of the diet every morning } \\
\text { in addition to their } \\
\text { regular diet for four } \\
\text { weeks. } \\
\end{array}$ & $\begin{array}{l}\text { Blood fluidity: } \\
\text { The mean of blood passage time before } \\
\text { and after treatment in the DBB group } \\
\text { significantly decreased, while no } \\
\text { significant change was observed in the } \\
\text { placebo group. }\end{array}$ & $\begin{array}{l}\text { The level of d-ROMs score, } \\
\text { shoulder stiffness symptoms, visual } \\
\text { fatigue symptoms: } \\
\text { There was a significant improvement } \\
\text { of d-ROMs score in the intervention } \\
\text { group after } 4 \text { weeks. There were no } \\
\text { significant changes of d-ROMs score } \\
\text { in the placebo group after } 4 \text { weeks. } \\
\text { There was a significant decrease in } \\
\text { shoulder stiffness symptoms at week } \\
3 \text { compared to week } 1 \text { in the DBB } \\
\text { group. There was a significant } \\
\text { decrease in visual fatigue symptoms } \\
\text { at week } 4 \text { of DBB ingestion } \\
\text { compared to week } 1 \text {. }\end{array}$ \\
\hline 14 & $\begin{array}{l}\text { Randomized } \\
\text { clinical trial, } \\
\text { pilot }\end{array}$ & $\begin{array}{l}\text { Fourteen healthy } \\
\text { women who all had } \\
\text { routine physical } \\
\text { check-ups, not on } \\
\text { chronic medication, } \\
\text { not overweight, and } \\
\text { on normal } \\
\text { omnivorous diets }\end{array}$ & $\begin{array}{l}\text { Group 1: The usual diet } \\
\text { and limited total calorie } \\
\text { intake to } 800-900 \\
\text { kcal/day for } 6 \text { weeks. } \\
\text { Group 2: The same as } \\
\text { group } 1 \text { calorie intake } \\
\text { and also consumed no } \\
\text { meat, fish, or products of } \\
\text { meat or fish for } 6 \text { weeks. }\end{array}$ & $\begin{array}{l}\text { Blood fluidity score, side effects: } \\
\text { During the first } 3 \text { weeks of diets, there } \\
\text { was no significant longitudinal change } \\
\text { within either group. In the second half } \\
\text { of the experiment, the BFS ( } 3 \text { vs. } 6 \text { - } \\
\text { week values) significantly increased in } \\
\text { group } 2 \text {, indicating an increment in } \\
\text { blood fluidity. By contrast, in group } 1 \text {, } \\
\text { there was a significant decrease during } \\
\text { the same time span (compared to } \\
\text { baseline, there were no significant } \\
\text { longitudinal changes in either group). } \\
\text { No side effects were reported during } \\
\text { the study. }\end{array}$ & \\
\hline
\end{tabular}

\section{Discussion}

Impairment of blood rheology has been shown to be associated with an increase in lifestyle-related diseases, such as dyslipidemia, hypertension, and cardiovascular diseases. Chronic diseases related to diet are the major causes of morbidity and mortality $(16,17)$. Nutritional science can help to advance the food system, minimize risks, maximize benefits, and deliver a safe, nutritious, and abundant food supply to safeguard human health (18). Several explorative studies have focused on the role of diet in various diseases including diabetes, cardiovascular disease, nephropathy, and obesity. This review was conducted to evaluate the effect of diet on blood viscosity in healthy subjects. In this systematic review, three related trials were obtained. In these studies, the sample sizes were small and one study is an acute intervention within 5 hours. The study of Yoshizu Nozawa et al., showed the relation between diet and rheological characteristics of erythrocytes. The compounds of DBB, including abundant histidine 
and anserine with antioxidative actions, have a possible observed effect of DBB on circulation of peripheral blood. Peripheral blood circulation facilitates the exchange of oxygen and nutrients between tissue and blood. Oxidative damage to the erythrocyte membrane induces impairment in the flexibility of normal erythrocyte membrane deformability. The antioxidative activity of DBB may improve blood fluidity, leading to a more effective functioning of capillary blood vessels (13). Whole blood viscosity and plasma viscosity are the main determinants of blood flow rheology and may have roles in atherosclerosis, thrombosis, and ischemia (19). Blood viscosity (that increases with increasing HCT) is considered as an important determinant for oxygen transport and delivery. Increased number of erythrocytes can enhance platelet adhesion and endothelial deposition and could increase risk of thrombotic complications. On the other hand, high HCT accelerates atherogenesis by increasing serum lipids and deposition of large plasma proteins and platelets on the endothelium (3). There is increasing evidence that levels of plasma and whole blood viscosity are associated with both coronary heart disease and stroke risk, and total mortality (19). In order to maintain adequate blood flow and oxygen supply to each organ, the rheological characteristics of blood are important (20). In a trial study, the effect of a vegetarian diet on the fluidity of blood was confirmed by E. Ernst and A. Franz (1995). The mechanism of the action of a vegetarian diet on blood fluidity is the likely effect of antioxidants and low levels of saturated fats (14). Oxidative stress is defined as an imbalance between the generation of free radicals and reactive metabolites that are often named as oxidants or reactive oxygen species (ROS), and antioxidants as a defense system for destruction of these metabolites $(21,22)$. Both enzymatic and nonenzymatic strategies contributed in antioxidant defense. Non-enzymatic antioxidant defense such as vitamin $\mathrm{C}$, vitamin $\mathrm{E}$, vitamin $\mathrm{K}$, $\beta$-carotene, uric acid, and glutathione (GSH); and the major enzymatic antioxidants are superoxide dismutases (SOD), catalase, and glutathione peroxidase (GSH-Px) (23). Oxidative stress leads to damage of important biomolecules such as DNA, lipids, and proteins. While scavenging of free radicals, erythrocytes become damaged by oxidation, which expends endogenous-reducing substances and reduces the level of erythrocyte antioxidant glutathione and superoxide dismutase. The depletion of the antioxidant is accompanied by changes in hemorheological parameters (24). There is a positive correlation between total cholesterol and TG concentrations; and plasma or blood viscosity. High levels of TG and LDL-C impair permeability of erythrocytes, and induce erythrocyte aggregation (25). On the other hand, high Hct accelerates atherogenesis, by increased serum lipids and deposition of large plasma proteins and platelets on the endothelium (3). Following the consumption of green vegetables, the decrease in SFAs and increase in PUFAs found in erythrocyte membrane phospholipids, may be associated with rheological and functional changes in red blood cells in hypercholesterolemic patients (26). Lipid peroxidation of polyunsaturated lipids is one of the oxidative stress markers. Malondialdehyde (MDA), 4-hydroxy2-nonenol (4-HNE), and F2-isoprostanes; (as end products of lipid peroxidation), are detectable in blood. They have been used as a measure of oxidative stress. Unsaturated aldehydes produced from these reactions can modify cellular proteins and other components (21). The increased level of MDA indicated the degree of oxidative damage in the erythrocytes. MDA leads to crosslinking of protein, and changes the membrane structure and transmembrane transport, and consequently, can have a negative effect on membrane viscoelasticity, surface area to cell volume ratio, and inner viscosity (27). Peripheral blood circulation facilitates the exchange of oxygen and nutrients between tissue and blood. Oxidative damage to the erythrocyte membrane induces impairment in the flexibility for normal erythrocyte membrane deformability (13). The study by Ulrich Kalus et al., investigated the effect of an onionolive-oil maceration in healthy humans in order to evaluate the positive effects of this product on blood rheology. Results of the study showed the obvious influences of the maceration product on blood rheology and a significant reduction of plasma viscosity. The authors suggested that these effects are due to slight vasodilatation of onion-oil that leads to a volume shift from extra- to intravascular and makes for dilution of the blood (15). Inhibition of platelet aggregation in vitro by an aqueous extract of Allium cepa (onion) has been proven. Its mechanism of action is via inhibition of diphosphate, epinephrine, arachidonic acid, adenosine, and collagen-induced platelet aggregation. Other substances of onion including sulphur compounds, inhibited the formation of thromboxanes and the action of platelet activating factor (PAF) (28). The therapeutic properties and low toxicity of active ingredients of Allium have been confirmed. Onion has a combination of fructans, dietary flavonoids, and organosulphur compounds with functional benefits against diseases. Some of these benefits are reduction of blood fibrinogen concentration, enhancing of the blood's fibrinolytic activity, antioxidative activity, lipid peroxidation inhibition, and reduction of serum cholesterol, respiratory and skin infections, diabetes, neurodegenerative disorders, and other diseases (29). Olive-oil is a major source of oleic acid as a monounsaturated fat, and also has higher amounts of vitamin E as an antioxidant compared with animal fats (30). Saturated fat and cholesterol-rich diet impact haemodynamic parameters including plasma and blood viscosity, plasma triglycerides, and RBC deformability, which are associated with increasing the risk of circulatory disorders (31). The main olive-oil antioxidants are carotenoids and phenolic compounds. The fatty acid composition of olive-oil has been introduced as a healthy food (32). 


\section{Conclusions}

This study discovers the positive effect of diet on reduction of blood viscosity in healthy ones. This study will help the researcher to uncover the critical area of prevention and treatment of diseases associated with blood viscosity, but requires more research in this regard in the future, especially double-blind, randomized placebo-controlled trials indicating the short-term and long-term effects of different diets. Due to data heterogeneity and small number of studies, meta-analysis was impossible.

\section{Acknowledgments:}

The authors declare their gratitude to the central library of Mashhad University of Medical Sciences for providing access to the databases.

\section{Conflict of Interest:}

There is no conflict of interest to be declared.

Authors' contributions:

All authors contributed to this project and article equally. All authors read and approved the final manuscript.

\section{References:}

1) Mandal M. Rheology of Blood: Biophysical Significance, Measurement, Pathophysiology and Pharmcologic Therapy. World Journal of Pharmacy and Pharmaceutical Sciences. 2016; 5(6): 2165-84.

2) Chen G, Zhao L, Liu Y, Liao F, Han D, Zhou H. Regulation of blood viscosity in disease prevention and treatment. Chinese Science Bulletin. 2012; 57(16): 1946-52. doi: 10.1007/s11434-012-5165-4.

3) Skretteberg PT, Bodegård J, Kjeldsen SE, Erikssen G, Thaulow E, Sandvik L, et al. Interaction between inflammation and blood viscosity predicts cardiovascular mortality. Scandinavian Cardiovascular Journal. 2010; 44(2): 107-12. doi: 10.3109/14017430903171248. PMID: 19670036.

4) Cho YI, Cho DJ. Hemorheology and microvascular disorders. Korean circulation journal. 2011; 41(6): 287 95. doi: 10.4070/kcj.2011.41.6.287. PMID: 21779279, PMCID: PMC3132688.

5) Li Y, Tian XX, Liu T, Wang RT. Association between whole blood viscosity and arterial stiffness in patients with type 2 diabetes mellitus. Endocrine. 2015; 49(1): 148-54. doi: 10.1007/s12020-014-0451-3. PMID: 25312690.

6) Sloop G, Holsworth Jr RE, Weidman JJ, St Cyr JA. The role of chronic hyperviscosity in vascular disease. Therapeutic advances in cardiovascular disease. 2015; 9(1): 19-25. doi: 10.1177/1753944714553226. PMID: 25260890.

7) Hu FB. Dietary pattern analysis: a new direction in nutritional epidemiology. Current opinion in lipidology. 2002; 13(1): 3-9. doi: 10.1097/00041433-200202000-00002.

8) Sofi F, Cesari F, Abbate R, Gensini GF, Casini A. Adherence to Mediterranean diet and health status: meta-analysis. BMJ. 2008; 337: a1344. doi: 10.1136/bmj.a1344. PMID: 18786971, PMCID: PMC2533524.

9) Willcox DC, Willcox BJ, Todoriki H, Suzuki M. The Okinawan diet: health implications of a low-calorie, nutrient-dense, antioxidant-rich dietary pattern low in glycemic load. Journal of the American College of Nutrition. 2009; 28(sup4): 500S-16.

10) Carallo C, Irace C, De Franceschi MS, Esposito T, Tripolino C, Scavelli F, et al. The effect of HDL cholesterol on blood and plasma viscosity in healthy subjects. Clin Hemorheol Microcirc. 2013; 55(2): 223 9. PMID: 23076003.

11) Campbell TC, Parpia B, Chen J. Diet, lifestyle, and the etiology of coronary artery disease: the Cornell China study. The American journal of cardiology. 1998; 82(10): 18-21. doi: 10.1016/S00029149(98)00718-8.

12) Higgins J, Green S. Cochrane handbook for systematic reviews of interventions version 5.1.0. The Cochrane Collaboration. 2011; 5(0).

13) Nozawa $Y$, Ishizaki $T$, Kuroda $M$, Takahashi $K$, Ebihara $S$, Itoh $T$. Ingestion of dried-bonito broth ameliorates blood fluidity in humans. Journal of health science. 2007; 53(5): 543-51. doi: 10.1248/jhs.53.543.

14) Ernst E, Franz A. Blood fluidity score during vegetarian and hypocaloric diets - a pilot study. Complementary Therapies in Medicine. 1995; 3(2): 70-1. doi: 10.1016/S0965-2299(95)80002-6.

15) Kalus U, Pindur G, Jung F, Mayer B, Radtke H, Bachmann K, et al. Influence of the onion as an essential ingredient of the Mediterranean diet on arterial blood pressure and blood fluidity. Arzneimittelforschung. 2000; 50(09): 795-801. PMID: 11050695. 
16) Cordain L, Eaton SB, Sebastian A, Mann N, Lindeberg S, Watkins BA, et al. Origins and evolution of the Western diet: health implications for the 21st century. Am J Clin Nutr. 2005; 81(2): 341-54. PMID: 15699220.

17) Hitsumoto T. Factors affecting impairment of blood rheology in obese subjects. Journal of cardiology. 2012; 60(5): 401-6. doi: 10.1016/j.jjcc.2012.06.012. PMID: 22884686.

18) Floros JD, Newsome R, Fisher W, Barbosa - Cánovas GV, Chen H, Dunne CP, et al. Feeding the world today and tomorrow: the importance of food science and technology. Comprehensive Reviews in Food Science and Food Safety. 2010; 9(5): 572-99. doi: 10.1111/j.1541-4337.2010.00127.x.

19) Peters SA, Woodward M, Rumley A, Tunstall-Pedoe HD, Lowe GD. Plasma and blood viscosity in the prediction of cardiovascular disease and mortality in the Scottish Heart Health Extended Cohort Study. Eur J Prev Cardiol. 2017; 24(2): 161-7. doi: 10.1177/2047487316672004. PMID: 27798361.

20) Okahara S, Soh Z, Miyamoto S, Takahashi H, Itoh H, Takahashi S, et al. A Novel Blood Viscosity Estimation Method Based on Pressure - Flow Characteristics of an Oxygenator During Cardiopulmonary Bypass. Artificial Organs. 2017; 41(3): 262-6. doi: 10.1111/aor.12747.

21) Rahal A, Kumar A, Singh V, Yadav B, Tiwari R, Chakraborty S, et al. Oxidative stress, prooxidants, and antioxidants: the interplay. BioMed research international. 2014; 2014. doi: 10.1155/2014/761264.

22) Kim KA, Yim JE. Antioxidative activity of onion peel extract in obese women: a randomized, doubleblind, placebo controlled study. J Cancer prev. 2015; 20(3): 202. doi: 10.15430/JCP.2015.20.3.202. PMID: 26473159, PMCID: PMC4597809.

23) Birben E, Sahiner UM, Sackesen C, Erzurum S, Kalayci O. Oxidative stress and antioxidant defense. World Allergy Organ J. 2012; 5(1): 9. doi: 10.1097/WOX.0b013e3182439613. PMID: 23268465, PMCID: PMC3488923.

24) Gyawali P, Richards RS. Association of altered hemorheology with oxidative stress and inflammation in metabolic syndrome. Redox Report. 2015; 20(3): 139-44. doi: 10.1179/1351000214Y.0000000120. PMID: 25494675.

25) Seki K, Sumino H, Nara M, Ishiyama N, Nishino M, Murakami M. Relationships between blood rheology and age, body mass index, blood cell count, fibrinogen, and lipids in healthy subjects. Clinical hemorheology and microcirculation. 2006; 34(3): 401-10. PMID: 16614464.

26) Okita M, Sasagawa T, Kotani M, Hayashi M, Yamashita H, Kimoto M, et al. Green vegetable juice increases polyunsaturated fatty acid of erythrocyte membrane phospholipid in hypercholesterolaemic patients. Asia Pacific journal of clinical nutrition. 2000; 9(4): 309-13. doi: 10.1046/j.14406047.2000.00161.x. PMID: 24394508.

27) Kasperczyk A, Słowińska-Łożyńska L, Dobrakowski M, Zalejska-Fiolka J, Kasperczyk S. The effect of lead-induced oxidative stress on blood viscosity and rheological properties of erythrocytes in lead exposed humans. Clin Hemorheol Microcirc. 2014; 56(3): 187-95. PMID: 23370159.

28) Al-Snafi AE. Therapeutic properties of medicinal plants: a review of plants with hypolipidemic, hemostatic, fibrinolytic and anticoagulant effects (part 1). Asian Journal of Pharmaceutical Science \& Technology. 2015; 5(4): 271-84.

29) Bisen PS, Emerald M. Nutritional and Therapeutic Potential of Garlic and Onion (Allium sp.). Current Nutrition \& Food Science. 2016; 12(3): 190-9. doi: 10.2174/1573401312666160608121954.

30) $\mathrm{Hu}$ FB. Plant-based foods and prevention of cardiovascular disease: an overview. Am J Clin Nutr. 2003; 78(3): 544S-51. doi: 10.1093/ajcn/78.3.544S. PMID: 12936948

31) Cicha I, Suzuki Y, Tateishi N, Maeda N. Effects of dietary triglycerides on rheological properties of human red blood cells. Clinical hemorheology and microcirculation. 2004; 30(3,4): 301-5.

32) Ramos-Escudero F, Morales MT, Asuero AG. Characterization of bioactive compounds from monovarietal virgin olive oils: relationship between phenolic compounds-antioxidant capacities. International Journal of Food Properties. 2015; 18(2): 348-58. doi: 10.1080/10942912.2013.809542. 